\title{
Commentary: The whole is greater than the sum of its parts
}

\author{
Michal Tabach
}

Published online: 24 August 2013

(C) Springer Science+Business Media Dordrecht 2013

In recent years, the international research community has focused growing attention on the learning and teaching of mathematics for young children. Among other means, this increased attention is demonstrated by special issues devoted solely to teaching and learning mathematics during early childhood. For example, the Journal of Mathematics Teacher Education published a special issue titled Windows to early childhood mathematics teacher education in an attempt to "build a research-based body of knowledge pertaining to the mathematics education of early childhood teachers" (Tsamir, Tirosh \& Levenson, eds., 2011, p. 89). The Journal for Didactics of Mathematics published a special issue focusing specifically on "current German/Austrian research in early childhood mathematics" (Peter-Koop \& Scherer, eds., 2012, p. 177). One might wonder, then, about the added value offered by the current special issue of Educational Studies in Mathematics titled Alternative perspectives on learning mathematics in the early years.

The uniqueness of this current special issue of Educational Studies in Mathematics stems from the fact that the five research papers it includes emerged from the same very large research center: the Individual Development and Adaptive Education research center established by the German Institute for International Educational Research at the Goethe University and the Sigmund Freud Institute. The focus of the project is on mathematics learning and the development of mathematical thinking in the early years. That is, two scientific disciplines that can be considered as relatively "neighboring" domains of study - educational psychology and mathematics education - joined together to conduct a deep cooperation within IDeA and some of the project's insights may be found in this issue. In other words, this issue describes the results of research carried out under two research traditions and using the same participants. As mentioned in the introduction to this issue, the joint effort was found to be more complex than could have been expected at first (Krummheuer, this issue).

The five research papers in this issue cover a range of topics, including mathematical creativity (Krummheuer et al.), gender differences (Lonnemann et al.), task design (Vogel), pedagogy (Brandt), and, finally, the development of mathematical thinking (Krummheuer). These papers present issues that are at the core of mathematics education in the early years and are based on a web of interconnections. Grevholm, Millman and Clarke (2008) claimed that what students learn is largely defined by the tasks in which they are engaged. This claim

M. Tabach $(\bowtie)$

Tel Aviv University, Tel Aviv, Israel

e-mail: tabachm@post.tau.ac.il 
regarding the centrality of tasks as a springboard for mathematical development was originally made in reference to a different age group. In my view, it holds for learning and teaching mathematics for young children as well. Hence, I have taken Vogel's study as a point of reference and I refer to it as I explore some of the links among the studies in this issue.

Vogel explicitly declares that "the mathematical situations of play and exploration are developed as a type of empirical research instrument, which gives the children the opportunity to express their mathematical (creative) potential." That is, while the situations are embedded in a playful context, they also have potential for the exploration and development of children's mathematical thinking. Vogel's reference to children rather than the child reflects her social constructive perspective on learning. Vogel goes on to characterize such situations according to three components: "(1) the mathematical task or problem, (2) the material-spatial arrangement, and (3) the multimodal stimuli (spoken language, gestures, and acting) of the guiding adult." As she herself claims, the third component is challenging because each situation is open-ended and can develop in several directions according to the participating children.

Vogel could have chosen to describe one such situation from these three structural aspects and report on its implementation with children. Alternatively, she could have described the longitudinal dimension of her study by following the same group of children acting within the same situation along the six data collection points. However, she chose to present three different situations of play and explorations carried out by different children and possibly with a different adult. Each situation serves to highlight one particular issue. The "wooden stick" situation serves to show that while engaging with the situation, the children were able to bring their own context to the mathematical world. The "solid figures" situation was used to demonstrate that while engaging with the same situation students change their mathematical interpretation as they continue to play. Moreover, the work of two girls in this situation of play and exploration was recorded on two different dates and is used to demonstrate how the researchers analyze, present and compare the children's interpretations. Finally, the work of two children on the "golden treasure" situation was presented to demonstrate the playful nature of the situation.

On the one hand, the reader is impressed by the large amount of work done, of which this paper is but "the tip of the iceberg" in terms of theory, design, data collection, and methods of data analysis. Also, the potential for further analysis of the data is huge. On the other hand, only small glimpses of the situations and their implementations were provided, thus encouraging the reader to follow Vogel's future work to learn more about these fascinating issues.

Lonnemann, Linkersdörfer, Hasselhorn, and Lindberg interviewed children in their last year prior to entering elementary school. A major aim of their research was to study the relationships between gender and mathematical achievements. They evaluated mathematical achievements with respect to numerical competencies. The sequence of tasks used during the interviews include: Arabic digit naming, knowledge of the sequence of numbers, the concept of quantities, seriation of quantities, and the ability to compare numbers with respect to their magnitude. In addition, the researchers measured reasoning abilities by presenting sets of three to five pictures and asking the child to point at the item which did not belong to the presented set. The analysis of the children's performance indicates that boys performed better. Further examination of the frequencies of girls and boys in the low, middle, and high levels of performance disclosed differences in both tails but not in the middle of the distribution.

A comparison of the study by Vogel and the one by Lonnemann et al. reveals fundamental differences. At the social level, working with one child at a time highlights a different perspective on learning than does working in tandem or with groups of four children. While Lonnemann et al. considered the child's knowledge at the time of the interview, Vogel considered the children's 
knowledge at their zone of proximal development (Vygotsky, 1978), as she is interested in the collective work of peers and a guiding adult. This difference is also linked to the data collection procedure. While Lonnemann et al. interviewed each child for $1 \mathrm{~h}$, Vogel videotaped the children at six different points in time. At the mathematical level, the tasks used by Lonnemann et al. had one mathematically correct answer, and each child's responses were coded as correct or incorrect. In Vogel's situations, one can hardly point to any specific mathematical result that can be considered correct. At the analysis level, in the Lonnemann et al. study, a total score was calculated for each child and all the scores were subject to statistical analysis. Hence, a general picture of the whole group of children could be provided. Vogel's study, on the other hand, did not aim at providing such an overall statement. Rather, she wanted to convey the depth and breadth of engagement in mathematics that can be achieved with very young children based on careful design and enactment of playful situations.

These differences, among others, clearly demonstrate the significance of a joint project carried out in two scientific disciplines. Vogel's study is well positioned in the mathematics education research tradition, while Lonnemann et al.'s study is positioned in the developmental psychology research tradition. As reported by Krummheuer in the introduction to this issue, the different epistemologies and ontologies were also notable during the course of the project itself. As a way of bridging the two disciplines, one can only speculate about the possibility of using Lonnemann et al.'s results as data to inform decision-making, for example about how to create multiple ability groups of students to engage in Vogel's mathematical situations of play and explorations. In other words, the end point of one study may be integrated into another study, even if they are rooted in two different disciplines.

The paper by Krummheuer, Leuzinger-Bohleber, Müller-Kirchof, Münz, and Vogel used two mathematical situations of play and exploration that were not reported in the paper by Vogel as single author. Hence, the reader of the two papers benefits twice: by learning about two more examples of such situations and by gaining a deeper understanding of the design underlying the two situations used by Krummheuer et al. Leikin (2009) claims that creativity may be fostered by the use of multiple solution tasks. In this sense, the mathematical situations of play and exploration meet this criterion. Realization of the situation's potential is exemplified by two examples taken from the work of one child, René, within a group of children. René's mathematical ideas while working with other children are analyzed to highlight their innovative and creative nature.

The theoretical foundations of this paper are uniquely rooted in the two scientific disciplines. On the one hand, the paper draws on the psychoanalysis perspective in attachment theory, which refers to personal characteristics that are identified based on an intelligence test and a cognitive assessment instrument for preschool children. On the other hand, it draws on the sociocultural perspective in creative mathematical thinking. Due to this unique integration of theoretical perspectives and the careful analysis of René's creative mathematical thinking, this paper makes a valuable contribution to the special issue in particular and to research in both scientific disciplines in general.

The issue of pedagogy is central to Brandt's paper. The study is based on two theoretical approaches to pedagogy as suggested by Bruner and by Rogoff - two researchers who draw on Vygotsky. One approach is based on everyday pedagogical practices and on the notion of "folk pedagogy" as proposed by Bruner, a psychologist by education and research interests. The second is the instructional models approach put forward by Rogoff, an educator who has attempted to bridge psychology and anthropology in her research. Indeed, the theoretical background of this paper thoroughly integrates these two approaches by referring to the learner's role, the instructor's role, the essence of learning, and the responsibility for the learning 
process. This theoretical synthesis of two approaches is then substantiated by empirical findings. Three learning episodes are provided and analyzed to illustrate the theoretical considerations presented earlier.

Brandt chooses not to use Vogel's situations of mathematical play and exploration in her research. This choice is somewhat puzzling when considering the efforts to develop these situations under the umbrella of the same research project. In a way, Brandt's approach is anthropological in that she attempts to capture everyday situations of mathematical practice as they unfold in kindergarten and then to conceptualize what happened through her clear, well-developed and innovative lens. Her final conclusion is that "the children's mathematical epistemology is formed through the pedagogical practices of their teacher."

Finally, Krummheuer aims to "generate a theory of the development of mathematical thinking of children in the early years" by drawing on his own concept of "Interactional Niche in the Development of Mathematical Thinking" (NMT). The NMT concept is composed of three components (content, cooperation, and pedagogy and education), which unfold with respect to two aspects (allocation and situation). In this paper, Krummheuer restricts the discussion to the components of content and cooperation, leaving pedagogy out. In fact, Brandt's paper can be placed directly under the pedagogy \& education component. In this sense, the two papers complement one another nicely. This is again a clear case of how theories, presented side by side within the same project, can have mutual influences.

The data for this paper involve two episodes, one taken from a previous project and one from the current project. The episode taken from the current project seems to have the same outline characteristics as those discussed by Vogel. [If this is indeed the case, the reader is offered another glance into a situation of play and exploration.] The two episodes are used to illustrate the main theoretical ideas advanced by Krummheuer in the paper, thus paralleling the structure of Brandt's paper. Krummheuer claims that argumentation in students' mathematical thinking develops from diagrammatical argumentation to narrative argumentation.

From a more general perspective, Krummheuer's personal assumption regarding the development of children's mathematical thinking is that "mathematical thinking in its developed practice and its accompanying form of argumentation should... contain diagrammatic as well as narrative elements. Evidently, these two forms of argumentation appear successively in child development." Restricting the suggested theory to the development of mathematical thinking in children aged 3-10 is related to Krummheuer's final statement in his introduction to this special issue and to the abandonment of attempts at formulating a general theory of mathematical thinking development. Rather, he advocates "initiation of a distinctively pragmatic orientation towards problems of local range or scope."

Let us now return to the question with which I opened this commentary regarding the added value of the current special issue as rooted in one research center. I have attempted to reveal parts of the web of connections underlying the five research papers: the development of mathematical situations of play and exploration stemming from a well-developed theoretical stand that is implemented and analyzed; the use of theoretical strands stemming from psychology and education as a basis for new and innovative approaches for theorizing and making sense of observed phenomena; and the compilation of papers that provide the reader a complementary view of the research efforts. Above all, the reader is given a chance to learn about the project and its many facets as one whole, which I believe to be greater than the sum of its parts. Such occasions are rare and I would like to thank Prof. Krummheuer for his efforts in putting forth this issue. 


\section{References}

Grevholm, B., Millman, R., \& Clarke, B. (2008). Function, form and focus: The role of tasks in elementary mathematics teacher education. In B. Clarke, B. Grevholm, \& R. Millman (Eds.), Tasks in primary mathematics teacher education (pp. 1-5). New York: Springer.

Leikin, R. (2009). Exploring mathematical creativity using multiple solution tasks. In R. Leikin, A. Berman, \& B. Koichu (Eds.), Creativity in mathematics and the education of gifted students (pp. 129-145). Rotterdam: Sense Publishers.

Peter-Koop, A., \& Scherer, P. (Eds.) (2012). Early childhood mathematics teaching and learning. Journal for Didactics of Mathematics, 33, 175-179

Tsamir, P., Tirosh, D., \& Levenson, E. (Eds.) (2011). Special issue: Windows to early childhood mathematics teacher education. Journal for Mathematics Teacher Education, 14(2), 89-92

Vygotsky, L. S. (1978). Mind in society: The development of higher psychological processes. Cambridge: Harvard University Press. 